MATEC Web of Conferences 46, 04002 (2016)

DOI: $10.1051 /$ matecconf/20164604002

(C) Owned by the authors, published by EDP Sciences, 2016

\title{
Fire safety engineering applied to high-rise building facades
}

\author{
Samuele Sassi ${ }^{1}$, Paolo Setti ${ }^{1}$, Giuseppe Amaro ${ }^{2}$, Lamberto Mazziotti ${ }^{3}$, Giuseppe Paduano ${ }^{3}$, \\ Piergiacomo Cancelliere $^{3}$ and Mauro Madeddu ${ }^{1}$ \\ ${ }^{1}$ FSC ENGINEERING SRL, Fire \& Structure Consulting, via A. Zezon, 4, Milano, Italy \\ ${ }^{2}$ GAE Engineering S.r.l. Corso G. Marconi, 20, 10125 Torino, Italy \\ ${ }^{3}$ Ministry of Interior, Italian National Fire Services, Largo Santa Barbara, 2, Rome, Italy
}

\begin{abstract}
Fire safety of high-rise building facades is a complex problem, therefore the use of prescriptive fire codes could not be sufficient to ensure a proper building fire safety level. In new high rise buildings the fire safety of facades can be taken into account by means of performance based fire design that can help in the selection of the best technological solutions and material choices.

This article deals with a case study done on the Piedmont Region Headquarters (TORRE REGIONE PIEMONTE) which is one of the highest office buildings in Italy. The "Torre Regione Piemonte" is located in Turin and has 45 storey and a total height of $183,61 \mathrm{~m}$. The building is characterized by the closed enclosure called "Grand Space" which is continuous for almost the entire height of the building and contains volumes such as offices/meeting rooms named as "Satellites".

In order to fulfil Italian fire safety requirements, the "Torre Regione Piemonte" building has been assessed using the performance base design and fire safety engineering approach. This paper deals with the design process selection of the most representative fire scenarios focusing on the fire resistance performance requirements of structural and glazed elements of the facades. Furthermore, all the simulation, calculations and performance fire resistant requirements of the high rise building have been supported by specific laboratory tests and experimental results, that are reported and discussed within paper.
\end{abstract}

\section{INTRODUCTION}

Fire safety of high-rise building facades is a complex problem; therefore the use of prescriptive fire codes could not be sufficient to ensure a proper building fire safety level. In new high rise buildings the fire safety of façades can be considered by means of performance based fire design that can help in the selection of the best technological solutions and material choices.

In this article, the façade of Piedmont Region Headquarters ("Torre Regione Piemonte", project of Arch. Massimiliano Fuksas, still under construction in Italy) is examined by fire safety engineering (FSE), as a case study due to its distinctive architectural and technological aspects.

The building is composed of a central part, used as offices (Office Area), which is next to a closed volume for the entire height named as "Grand Space". Inside this volume, there are box-shaped structures called "Satellite" used for meeting rooms connected with office areas.

This is an Open Access article distributed under the terms of the Creative Commons Attribution License 2.0, which permits unrestricted use, distribution, and reproduction in any medium, provided the original work is properly cited. 


\section{MATEC Web of Conferences}

The Office Area and the "Satellites" are built in reinforced concrete and pre-stressed concrete, enclosed by a aluminium/glass facade, on the other hand the "Grand Space" is enclosed by only a façade composed by a main steel frame and aluminum-glass cladding.

As the presence of "Grand Space" affects the fire behavior of the building, performance based design and FSE methods have been chosen to examine and conform the building "Torre Regione Piemonte" to the Italian fire safety requirements. More precisely, different fire scenarios have been considered both with respect to the effects on structures and to the occupants in order to optimize the choice of active and passive fire safety measures. In order to check the smoke and temperature distribution, 6 different fire scenarios have been performed by CFD. As a result, the passive fire protection of the critical points of steel structures are optimized and fire resistance characteristics of the façade are enhanced. In particular, according to the results of the scenarios, only Level -2 and level -1 of "Grand Space" steel structures had been protected with intumescent paint; glazed separations between Offices and "Grand Space" had been assessed for $\mathrm{EW} 60_{(\mathrm{i} \rightarrow \mathrm{o})}$ fire rating instead of EI 120 (preliminary requirement); glazed separations between Offices and "Satellites" had been assessed for EI 60 fire rating instead of EI 120.

Furthermore, the facade types used in the building are selected with respect to the fire resistance requirements derived from performance fire design and CFD models, taking into account also the effects due to the installation and weather conditions.

In the article, the fire resistance performance requirements of structural and glazed elements of the facades and the results of the CFD models are reported. In addition, all the simulated calculations and performance fire resistant requirements assessment process, have been supported by specific laboratory tests. These fire resistant tests have been also carried out in accordance with EN 1364-3 to evaluate the fire behaviour of the chosen glazed façade system.

\section{DESCRIPTION OF THE BUILDING}

"Torre Regione Piemonte" building is composed of 2 basement levels and has 43 storeys above ground level (max. height: $183.61 \mathrm{~m}$ ) with dimensions of $45 \times 45 \mathrm{~m}$. All space in the first three floor is allocated to entrance hall, consists of 2 mezzanine floors as exhibition areas. The upper floors are office areas. The 3 -D view and a typical plan are show in Fig. 1.

The building is composed of a central part, used as offices (Office Area), which is next to a closed volume for the entire height named as "Grand Space". Inside this volume, there are box-shaped structures called "Satellite" used for meeting rooms connected with office areas.

The Office Area and the "Satellites" are built in reinforced concrete and pre-stressed concrete, enclosed by a aluminium/glass facade, on the other hand the "Grand Space" is enclosed by only a façade composed by a main steel frame and aluminum-glass cladding.

According to the Italian prescriptive fire codes, the project fire safety requirement should fulfil the following fire safety measures:

- Each floor of the offices (except the double/triple height zone - entrance hall) should ensure a fire compartment with R/REI/EI 120 fire resisting class and the installation of mechanical smoke and heat exhaust systems and sprinklers.

- Each Satellite should ensure a fire compartment with R/REI/EI 120 fire resisting class, the installation of sprinklers and water curtain on glazing.

- Grand Space is the only volume that requires R 60 fire resisting class; it is composed of aluminum façade structure supported by steel elements and is equipped with mechanical smoke and heat exhaust systems.

- The façade between two macro areas (including the separation between Offices and Satellites) should have EI 120 fire resisting class. 

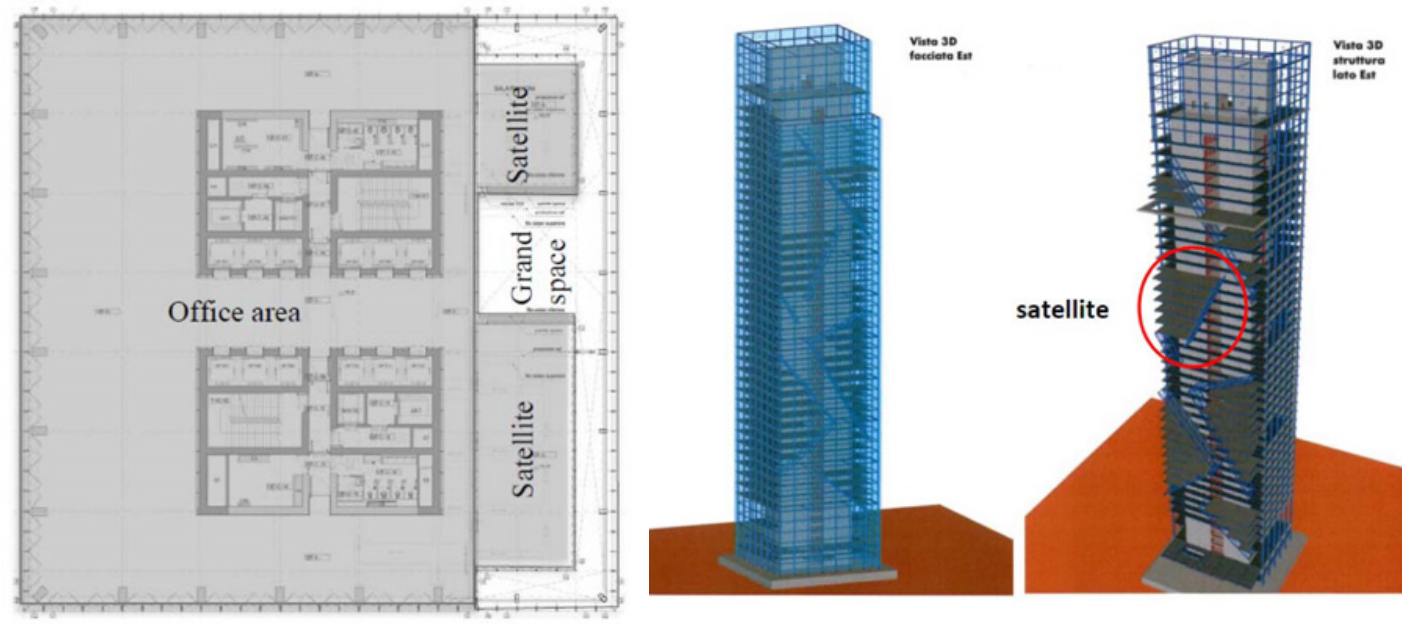

Figure 1. Typical plan of Tower Piedmont Region Headquarters where are highlighted Office Area, Satellites and Grand Space.

\section{CONSTRUCTIONAL AND FUNCTIONAL PROBLEMS}

During the construction phase of the building, there are three major problems also related with fire safety of the external façade.

- The first problem is the maintenance of fire proofing on the metal structure of Grand Space. Once the application of fire-proofing is completed there is no way of having an access to all parts of the structure.

- The second one is the possibility of having an alteration in the color of glazed elements of façade (fire resisting class EI 120) due to temperature changes in summer. In that case, it is difficult to replace the damaged glass panel with the new one.

- The last problem is the excessive additional load on load-bearing structure due to self weight of water curtain in the Satellite area, which can lead to further severe problems.

\subsection{Objectives of the fire safety measures}

In accordance to the Italian regulation the objectives of the taken measures to guarantee the fire safety of the façade are listed below by taking into account the problems mentioned in the previous sections:

- Avoiding the collapse of Grand Space structure for at least 60 minutes.

- Blocking fire propagation between different levels and Satellites.

- Guaranteeing the safety conditions for the occupants and fire rescue teams (fire brigades) in case of fire inside the Grand Space.

\subsection{Technical solutions}

In order to fulfill the specified fire safety objectives on each area the following solutions are implemented:

- Fire-proofing is applied only on accessible portion of the Grand Space structure and the structure is checked by FSE with partial fire-proofing to ensure its fire resistance. 


\section{MATEC Web of Conferences}

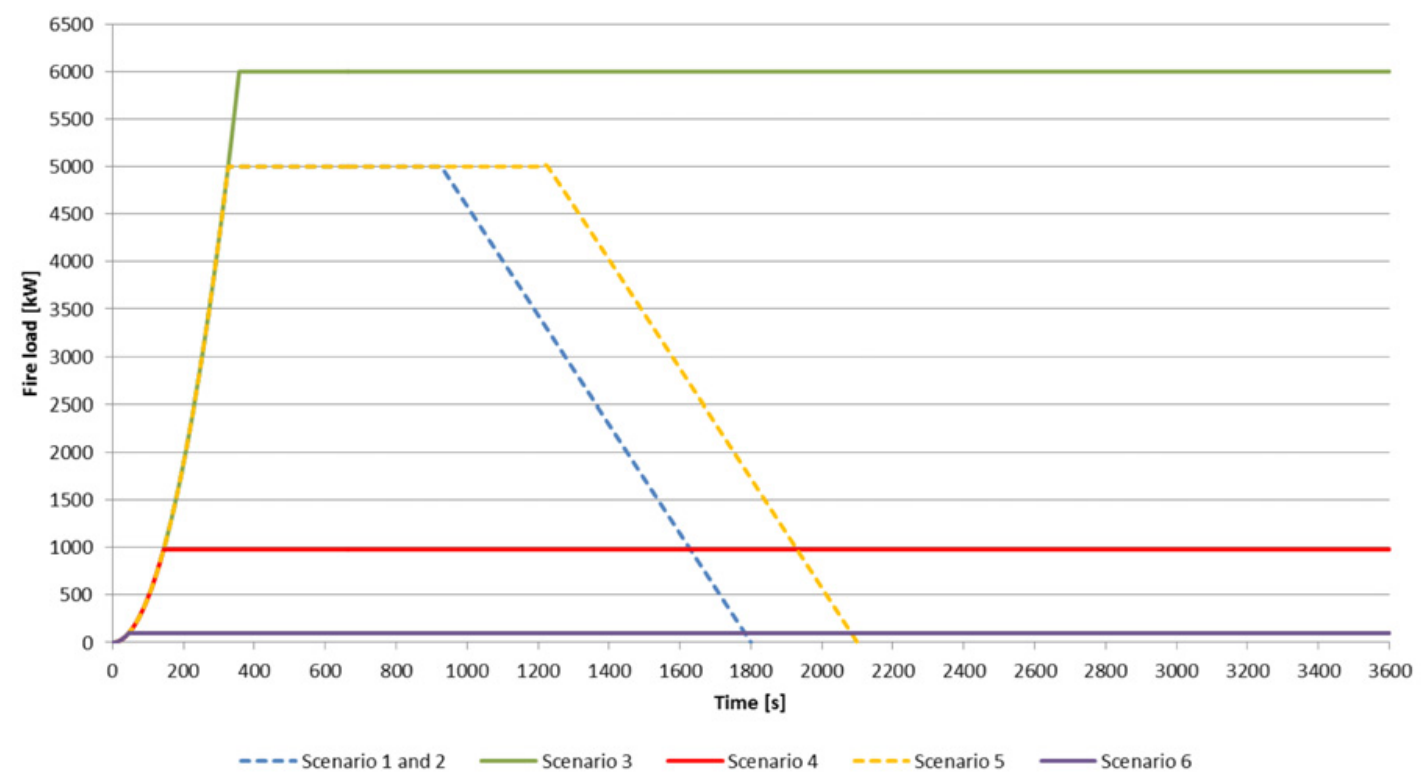

Figure 2. HRR define for the 6 selected scenarios.

- Performance class of the façades (among Offices - Satellites and Offices - Grand Space) is lowered from EI 120 to EI 60 for the areas where two sided fire is possible and where there is no excessive temperature rising during summer season.

- To eliminate the excessive additional load due to self weight of water curtain in the Satellite area water mist system is used instead of water curtain to suppress an outbreak of a fire in that area. Besides, Grand Space structure is also checked by FSE to ensure its fire resistance.

- Performance class of the façades (between Offices - Grand Space) is lowered from EI 120 to EW $60_{(i \rightarrow 0)}$ and the Grand Space structure is checked by FSE to ensure its fire resistance.

- Fire safety conditions are checked by FSE inside the Grand Space taking into account natural smoke and heat exhaust systems.

\section{CFD MODELS}

The geometry for the CFD models is based on 2D AutoCad drawings of the building. The CAD models is then transferred and used in the CFD software where a computational mesh is constructed. Mesh refinements are applied in and around the fire areas to ensure correct flame temperatures. The simulations are run on a large computer cluster to speed up the solution process.

Four models are assembled to simulate six different fire locations. In the following the fire scenarios are listed:

1) Fire in second basement level inside the Grand Space (scenario 1)

2) Fire in ground floor level inside the Grand Space (scenario 2)

3) Fire inside Offices (scenario 3 e 4)

4) Fire inside a Satellite (scenario 5 e 6 ).

Figure 2 report the Heat of Heat Released (HRR) for the 6 selected scenarios. 

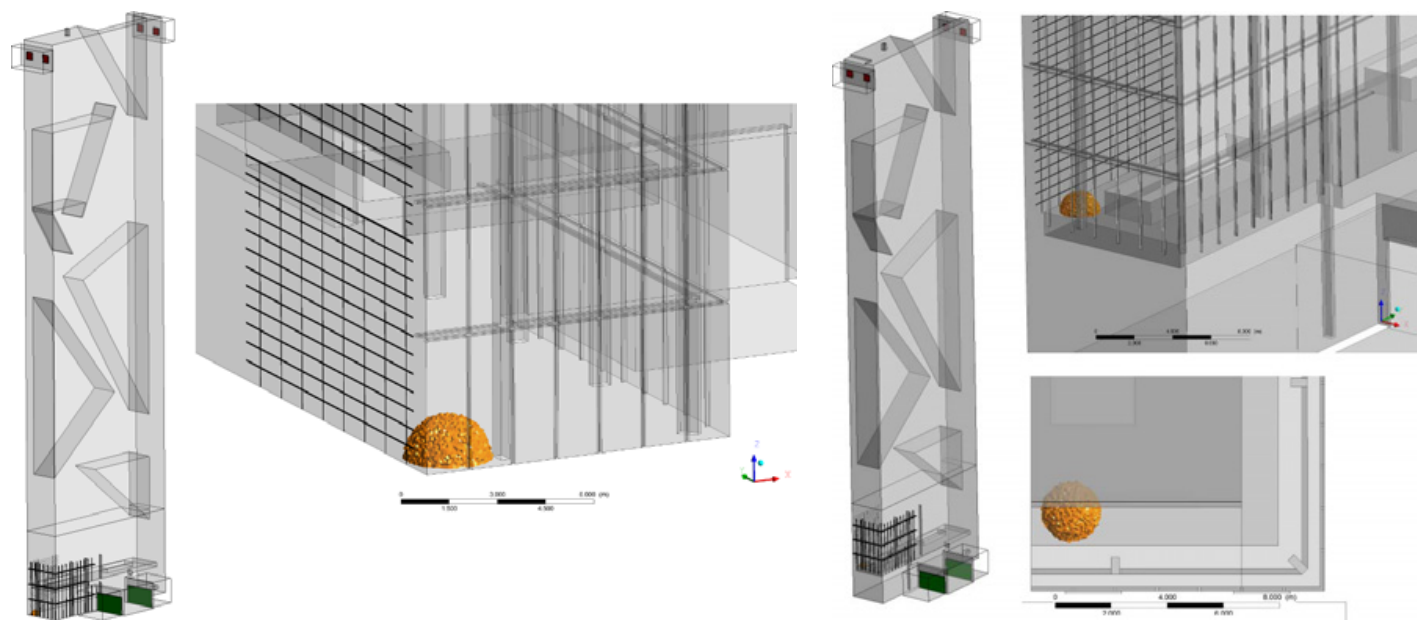

Figure 3. CFD models for the scenario 1 and scenario 2.

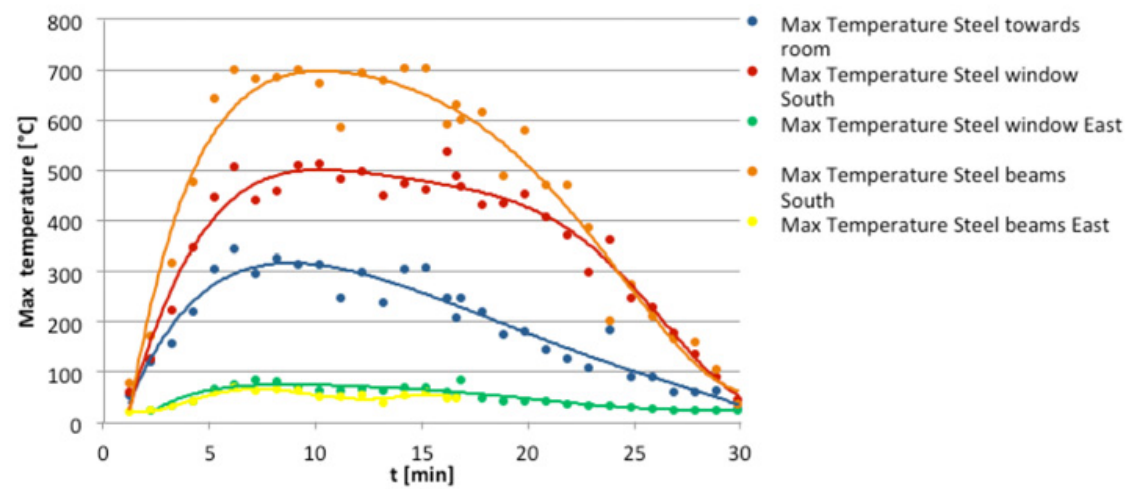

Figure 4. Maximum temperature on the steel at the eastern and southern part of the façade and the steel towards the adjacent room for the scenario 1 .

The present CFD calculations have been performed by CFD program ANSYS CFX in collaboration with Ramboll group.

\subsection{Scenario 1 and 2 - Fire inside the Grand Space}

The fire is located at level -2 (scenario 1) and at level 0 (scenario 2) inside the atrium close to the glass façade and steel structure. The fire development coefficient is $0.047 \mathrm{~kW} / \mathrm{s}^{2}$ and the fire effect is $5 \mathrm{MW}$. The fire thereby reaches maximum HRR after $326 \mathrm{~s}$. The HRR is kept constant for 10 minutes after it has reach maximum and then it starts to decay linearly. The openings for fresh air in the bottom and the openings for smoke ventilation in the top are open after 60 s. Figure 3 depicts CFD Models for the scenario 1 and scenario 2 .

For the fire location at level -2, the flame will stick very close to the southern steel structure in the façade and results in high temperature levels. This impingement of the flames results in high temperature level that can be maintain over a period of 20-25 min for this fire location as it can be seen on Fig. 4 . The main problem is that the flame is very close or touching the steel structure. 

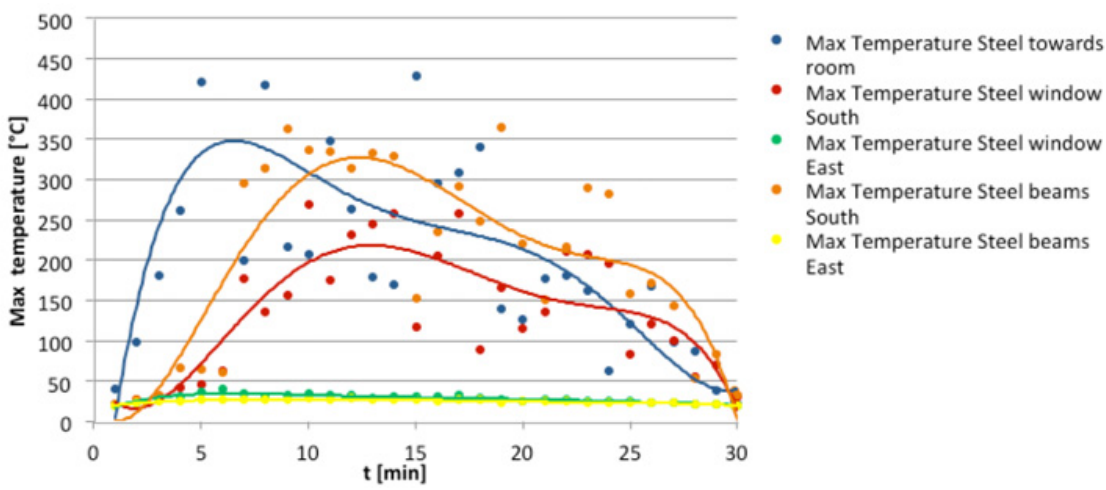

Figure 5. Maximum temperature on the steel at the eastern and southern part of the façade and the steel towards the adjacent room for the scenario 2 .

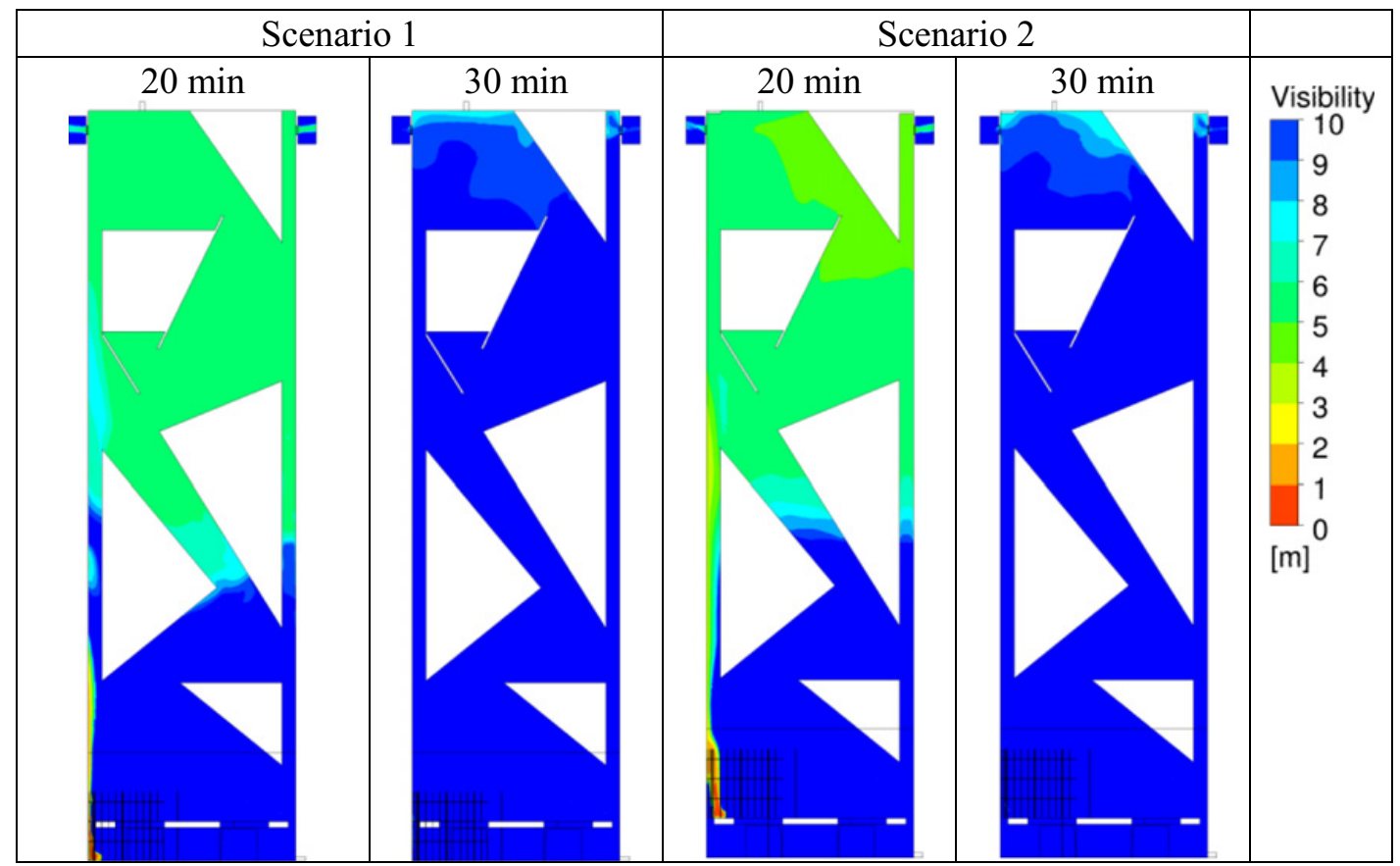

Figure 6. Visibility inside the Grand Space for the scenario 1 and scenario 2.

For the fire location at level 0, characterized by a $1 \mathrm{~m}$ of distance form Grand Space facades, the flame are not able to increase the temperature of the steel structure over the critical level.

The peak value for the maximum surface temperature of the steel towards south and the adjacent room is around $500^{\circ} \mathrm{C}-600^{\circ} \mathrm{C}$, as reported in Fig. 5 .

The visibility inside the Grand Space is shown on figure 6 at different times at $20 \mathrm{~min}$ to $30 \mathrm{~min}$ for Scenario 1 and Scenario 2. From Fig. 6, it can be seen that the visibility will not be critical in the occupied zone at level -2 and 0 . From the figure it can be seen that the atrium is filled with smoke since the visibility is reduced. This however occurs above the occupied zone on level -2 and 0 and is therefore not critical. 

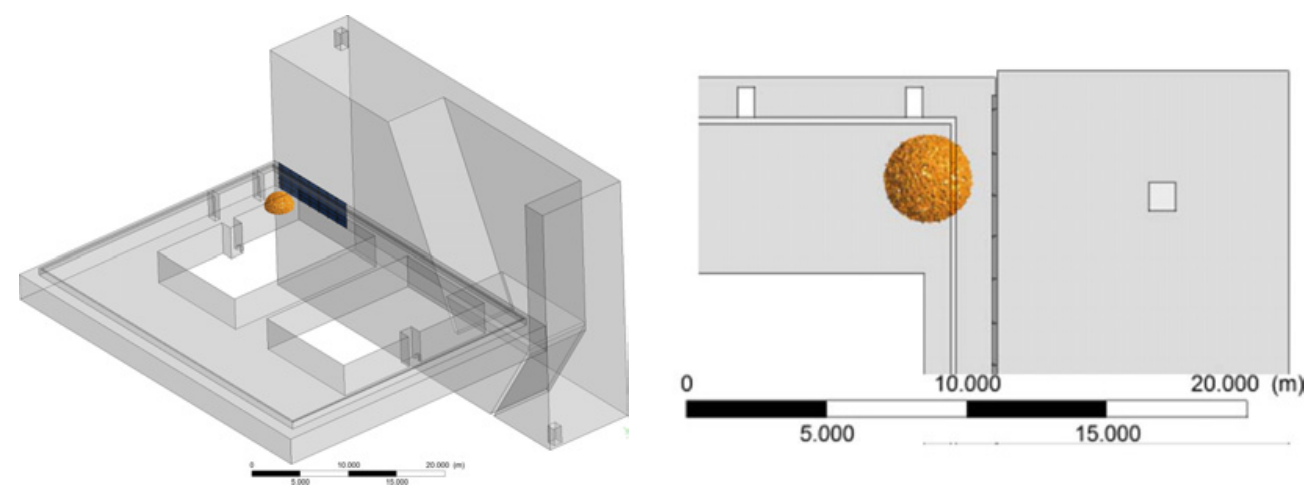

Figure 7. CFD model for the scenario 3 and 4.

As a result of the scenarios 1 and 2, it is necessary to protect steel structure of the Grand Space between level -2 and 0 to guarantee the R 60 fire resistance class. In addition, the presence of natural smoke and heat exhaust system makes certain the adequate level of safety inside the Grand Space in case of fire for evacuation of occupants and intervention of Fire Brigades.

\subsection{Scenario 3 and 4 - Fire inside office area}

The office is an open space office with a panorama view out to the atrium (Grand Space). The glass between the office area and the atrium is a fire resistance glass $\mathrm{EW} 60_{(\mathrm{i} \rightarrow \mathrm{o})}$. This means that the glass maximum allows an incident radiation less than $15 \mathrm{~kW} / \mathrm{m}^{2}$. In the model only the glass and steel in close proximity of the fire are modelled. The distance from the centrum of the fire to the atrium surface is around 2 meters. Figure 7 reports the CFD models for scenario 3 and scenario 4.

Including the adjacent atrium into the model makes possible to see the effects of the temperature and radiation from the fire on the steel structure of the atrium.

In the scenario 3 the sprinklers in the office area fail to operate and the fire develops to up to an HRR value of $6 \mathrm{MW}$. It reaches its maximum effect after $326 \mathrm{~s}$ and remains constant for 1 hour. The mechanical smoke ventilation starts after $40 \mathrm{~s}$ and reaches its full capacity after $100 \mathrm{~s}$. The incident radiation is shown in Fig. 8. The effect of the fire resistance glass $\left(\mathrm{EW} 60_{(\mathrm{i} \rightarrow \mathrm{o})}\right)$ is clear and reduces the radiation incident to the steel structure at the exterior façade. After 20 minutes the fire continues at the same fire load and so does the thermal radiation that not change much after this period. This can be seen on Fig. 8 where the incident radiation on the northern and eastern façade is given as a function of time.

The temperature at the external façade will increase with time after 20 min due to the accumulation of the thermal radiation in the atrium. However, after some time the air convection mechanism due to the airflow helps limiting the temperature levels of the external façade. The temperature development on the façade is given on the right side of Fig. 8.

In the scenario 4 , made for checking the tenability condition of the occupants inside the office, the sprinklers are activated after $148 \mathrm{~s}$ decreasing the HRR from $6 \mathrm{MW}$ to $0.98 \mathrm{MW}$. The fire development coefficient is $0.047 \mathrm{~kW} / \mathrm{s}^{2}$. The smoke ventilation is activated after $40 \mathrm{~s}$ and reaches its full capacity after $100 \mathrm{~s}$. The visibility is reduced in 5 minutes and the temperature would be critical in only 8 minutes.

The results of the scenarios 3 and 4 show that it is not necessary to protect the steel elements of the Grand Space since the façade EW $60_{(\mathrm{i} \rightarrow \mathrm{o})}$ is able to reduce their temperature. Therefore, the presence of EW $60_{(i \rightarrow 0)}$ façade hinders vertical propagation of fire from "office area". 
$8 \min$
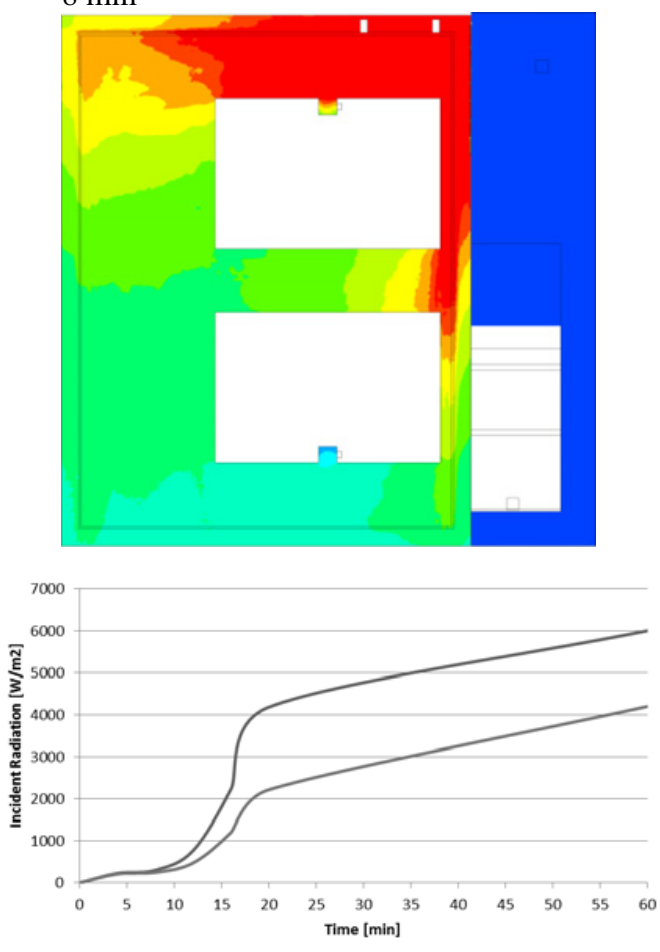

- facade 1 -facade 2
$20 \mathrm{~min}$
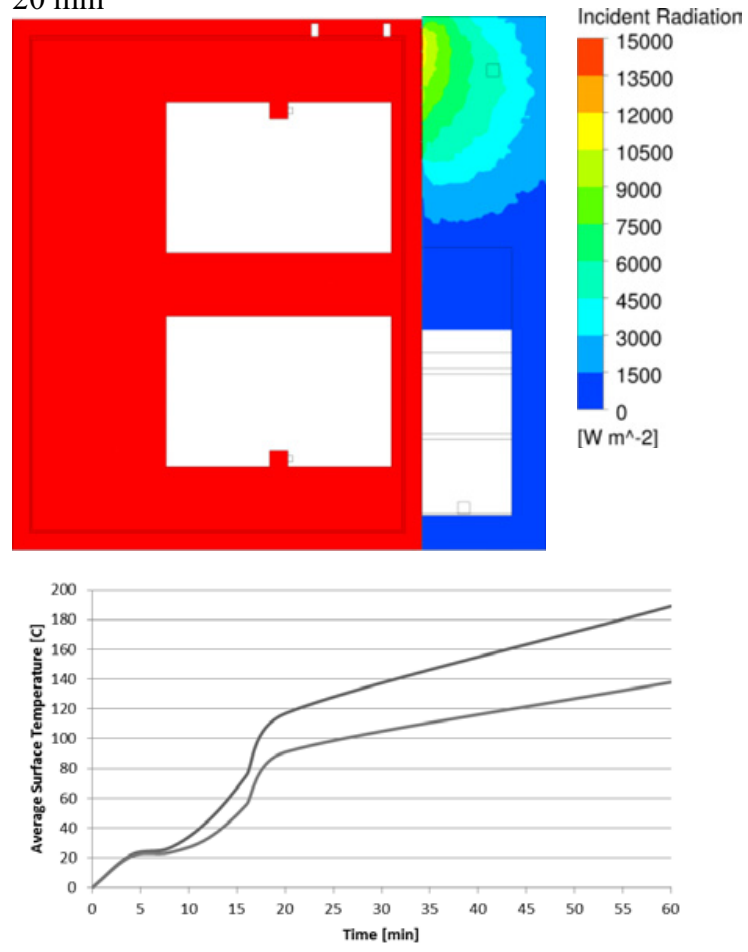

—facade 1 -facade 2

Figure 8. Incident radiation and temperature at façade 1 and 2 - scenario 3.

\subsection{Scenario 5 and 6 - Fire inside Satellite}

In the Satellites there are doors which connect the meeting room to the office area. In the meeting room the glass façade are mounted on a steel frame through the atrium and the office area. The glass of the meeting room is normal glass without any kind of fire resistance properties.. The problem is sketched on Fig. 9.

The main focus for a fire in the meeting room with failure of the water mist system is to see the temperature effects on the steel structure at the external glass façade. Therefore the model only consists of the air volume outside the meeting room including the steel structure. The heat from the fire is then applied on the surface of the glass in the meeting room through the atrium space.

In the scenario 5 the water mist system fails in the meeting room and the HRR load reaches $5 \mathrm{MW}$ and remains constant for 15 minutes and then starts to decay.

The average surface temperature on the steel has a peak value around at $80^{\circ} \mathrm{C}$ for a period of around 15 minutes. The peak value for the maximum surface temperature on the steel structure is $140^{\circ} \mathrm{C}$ for around 15 minutes. For the steel structure at the southern façade the peak value for average surface temperature is $110^{\circ} \mathrm{C}$ for 15 minutes and the peak value for maximum surface temperature is $200{ }^{\circ} \mathrm{C}$ for 15 minutes period. No temperatures above $300^{\circ} \mathrm{C}$ are registered for any of the steel structure surfaces under consideration. Figure 10 shows the maximum surface temperature on steel at the façade for the scenario 5 .

In the scenario 6, made for checking the tenability condition of the occupants inside the satellite, it is assumed there are no fire ventilation in the meeting room and the water mist activates and thereby reducing the HRR from $5 \mathrm{MW}$ to $0.1 \mathrm{MW}$. The fire growth coefficient is $0.047 \mathrm{~kW} / \mathrm{s}^{2}$. 

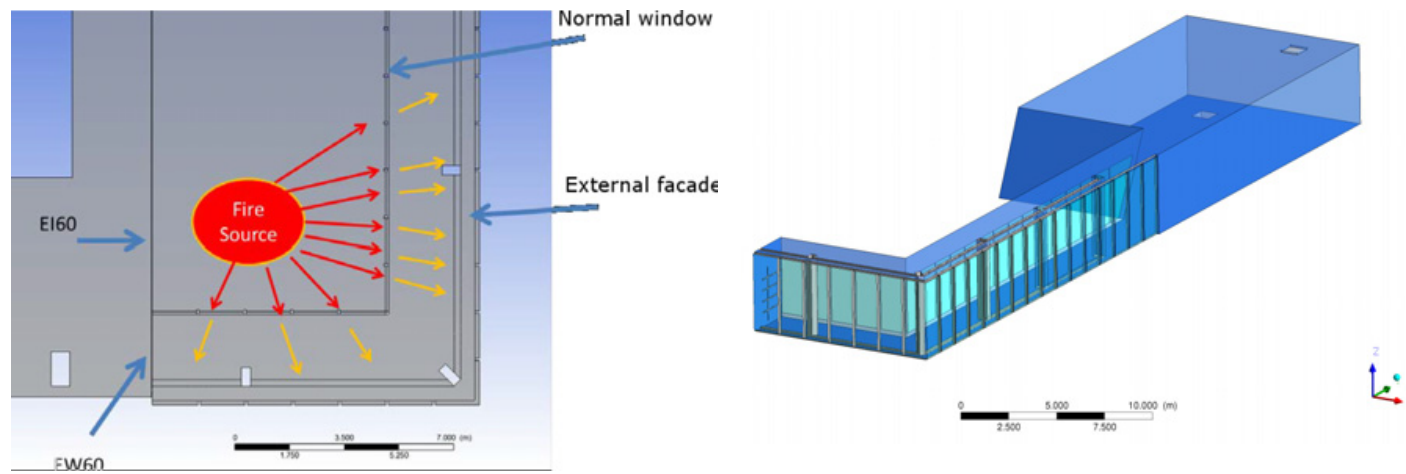

Figure 9. CFD model for the scenario 5 and 6.

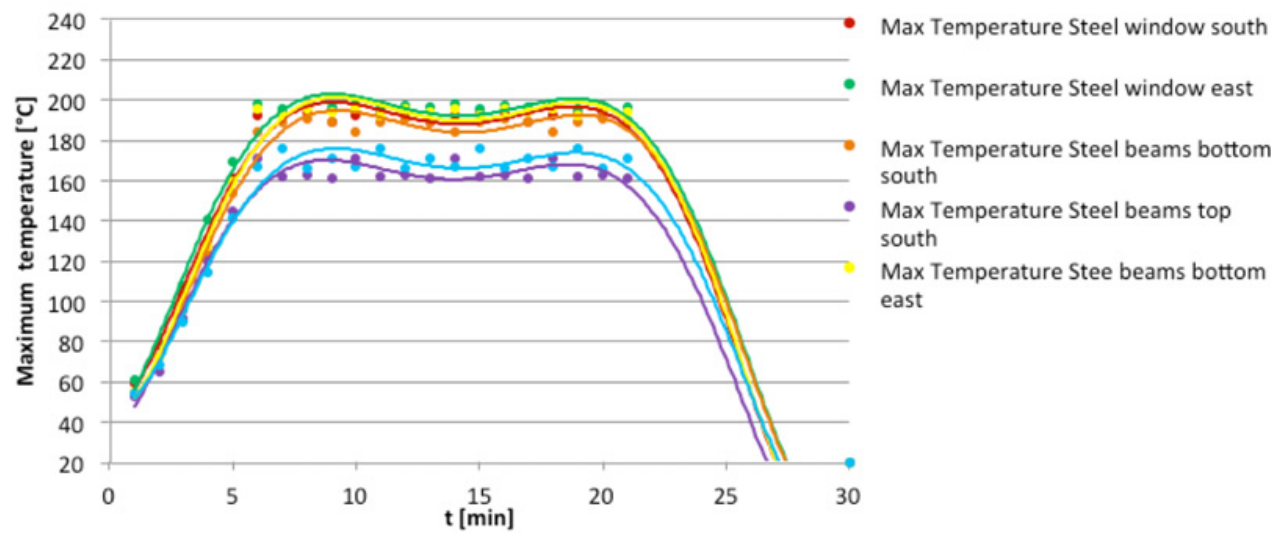

Figure 10. Maximum surface temperature on steel at the façade for the scenario 5.

The visibility is critical in the meeting room after 2 minutes and the temperature would be critical in most of the meeting room after 4 minutes.

The results of the scenario 5 and 6 show that temperatures of steel members of the Grand Space does not exceed the critical limits in case of a fire inside a Satellite. Therefore, it is not necessary to protect the steel elements as it guarantees fire resistance class R 60 without any fire protection. The presence of water mist system enhances the actual fire safety conditions to prevent fire propagation at higher levels or inside the Grand Space.

\section{SPECIFIC LABORATORY TESTS}

In order to guarantee the performance class EW $60_{(\mathrm{i} \rightarrow 0)}$ in the glazed façades between Offices and Grand Space, the fire resistant glazed panels (without intumescent gel coat) with a special composition to hinder possible color variations in summer conditions is taken into consideration.

A specific test in accordance to EN 1364-3 is performed to check fire performance of panels with respect to the CFD models. In Fig. 11 a typical node of façade, the lay-out of the test and the radiation curve obtained during the fire test are shown. 

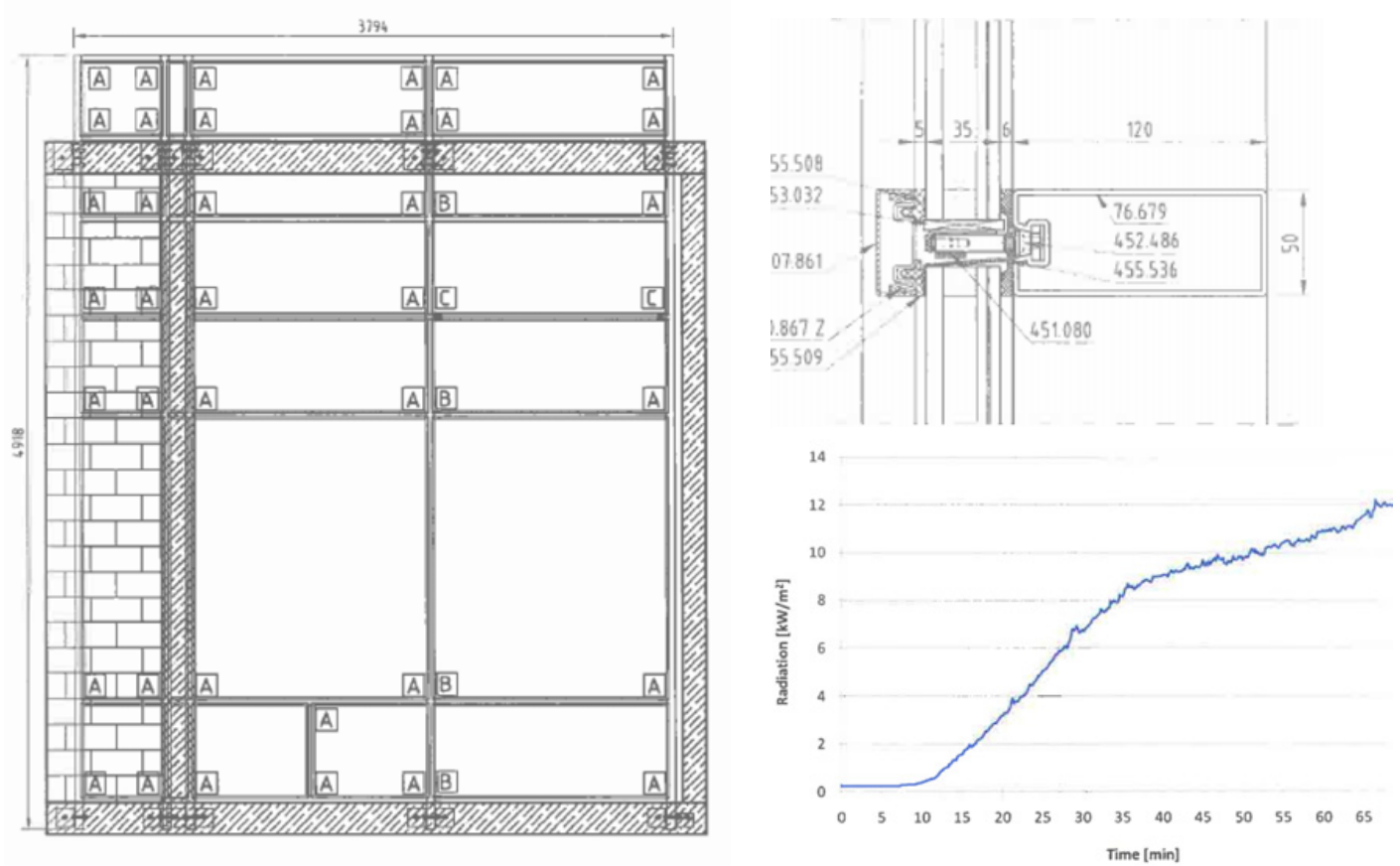

Figure 11. Lay-out of the test (left), typical node of façade (right-top), radiation curve (right-down).

\section{CONCLUSION}

Fire safety of high-rise building façades is a complex problem, therefore the use of prescriptive fire codes could not be sufficient to ensure a proper building fire safety level. This article emphasizes that FSE and CFD fire modeling are used in a real case as useful tools to solve fire safety problems of façades addressing the fire safety level of the overall building.

The case analyzed in the "Torre Regione Piemonte" gives some opportunities to optimize construction technology and fire safety measures in order to fulfill the required safety objectives in accordance to the Italian national fire codes.

The results of the fire scenarios show that fire protection of the steel elements can be made most efficient. It has be seen that there is need of fire protection on Grand Space façade only from level -2 to 0 . Furthermore, the presence of $\mathrm{EW} 60_{(\mathrm{i} \rightarrow \mathrm{o})}$ façade and water mist system provide the required fire safety conditions in case of an outbreak of a fire for higher building levels.

In addiction, CFD models are performed to optimize the smoke and heat exhaust systems inside the Grand Space and hence, the fire resistance class of the separating façade between Offices and Grand Space can be reduced from EI 120 to EW $60_{(\mathrm{i} \rightarrow 0)}$.

This case study confirms that performance based approach makes possible to analyze façades complexly, to guarantee the fulfillment of the required fire safety level and to optimize cost and time of construction, reducing the overall maintenance cost and maintenance time of the building.

\section{References}

[1] Fuksas, http://www.fuksas.it/home.htm\#/progetti/0401/, last checked 14 January 2014.

[2] User Manuel Ansys CFX14.0, Ansys CFX-International, 2012. 
$2^{\text {nd }}$ International Seminar for Fire Safety of Facades, Lund (Sweden), 2016

[3] Mathematical Model and Solution Algorithms Manual, Ansys 14.0, Ansys CFX-International, 2010.

[4] Drysdale, D., Fire Dynamics, John Wiley \& Sons, Chichester, 1985.

[5] Mulholland G.W.: Smoke production and properties in DiNenno P.J., et al, Editors, SPPE Handbook of Fire Protection Engineering, 2. Edition, Chapter 15, Section 2. pp. 217-227, 2002.

[6] Leif Staffanson, Selecting design fires, Department of Fire Safety Engineering and Sys-tems Safety, Lund University, 2010.

[7] Boverket, Boverkets allmänna råd 2011 - Vägledning i analytisk dimensionering av byggnaders brandskydd, 2011.

[8] Calculating smoke potential for use in Argos, Danish Institute of Fire and Security Tech-nology, Bjarne Husted, 2004. 